\title{
Midazolam and haloperidol for palliative sedation: physicochemical stability and compatibility of parenteral admixtures
}

\author{
Gabriel Estan-Cerezo*1, Francisco José Rodríguez-Lucena ${ }^{1}$ Carmen Matoses Chirivella ${ }^{1}$, \\ Inmaculada Jiménez-Pulido ${ }^{1}$, Ana García-Monsalve ${ }^{1}$, Andrés Navarro-Ruiz ${ }^{1}$
}

${ }^{1}$ Servicio de Farmacia-Hospital General Universitario de Elche-FISABIO, Camino de la Almazara, Elche, Spain

\begin{abstract}
This study was done to determine the time while the binary admixtures with midazolam and haloperidol drugs are administered by perfusion to the patients in the clinical routine. Samples with different concentrations of both drugs were prepared following the usual clinical practice. Solvents used were $0.9 \%$ sodium chloride solution and $5 \%$ dextrose, and viaflo plastic bags were used as the containers of the admixtures. Samples were not protected from light and were stored at $20{ }^{\circ} \mathrm{C}$ or at $4{ }^{\circ} \mathrm{C}$. Compatibility and physicochemical stability were studied by visual inspection, turbidity measurement, $\mathrm{pH}$ determination and ultraviolet detection high performance liquid chromatography (UV-HPLC) was used to determine midazolam and haloperidol concentrations. The assay was validated following the FDA and EMA guidelines. Darunavir was used as internal standard (IS). For the studied admixtures, turbidity measurements and $\mathrm{pH}$ determinations showed little changes in function of the time. Haloperidol and midazolam concentrations determined by HPLC are within the acceptable range of drug concentrations, which are considered stable for four days in case of admixtures stored at $20^{\circ} \mathrm{C}$ and for seven days for refrigerated admixtures. Taking into account the microbiological risk matrix, the compatibility and the chemical and microbiological stability of the midazolam and haloperidol in the co-administered admixtures in viaflo plastic bags with $0.9 \%$ sodium chloride solution and $5 \%$ dextrose can be set as 48 hours when samples are stored at $20{ }^{\circ} \mathrm{C}$ and one week if they are refrigerated.
\end{abstract}

Keywords: Midazolam/pharmacology. Haloperidol/pharmacology. HPLC/methods. Additives in Sanitizing Products. Chemical stability. Physical stability. Physicochemical properties.

\section{INTRODUCTION}

Sedation is understood in the palliative care context as a deliberate administration of drugs in the required doses and combinations to reduce patient's awareness with advanced or terminal disease (De Graeff, Dean, 2007). The most frequent indication of terminal sedation is the presence of refractory symptoms such as dyspnea, delirium, pain and psychological distress. Pharmacological treatment will depend on the detected refractory symptom.

Drug stability studies are needed when they could be administered together at ambient temperature for parenteral dosage. Furthermore, the influence of the material were the solutions are contained has to be taken into account. The currently employed materials for clinical use such as

\footnotetext{
*Correspondence: G. Estan-Cerezo. Servicio de Farmacia-Hospital General Universitario de Elche-FISABIO, Camino de la Almazara, n.11, 03203, Elche, Spain. Tel/fax: 0034 966616909. E-mail: gabrielestan@gmail.com
}

glass or plastics as PVC, PP or elastomer material and their influence in the stability of the drugs are usually studied. Additionally, stability can be different when different concentrations of the drugs are employed. Then, the study of the stability has to include the expected concentrations in the clinical use (Trissel, 1983). Usually, the chemical stability of a drug is acceptable when the amount of the drug is from $90 \%$ to $110 \%$ of the initial value (Jenke, 1996).

Midazolam is the most used drug in palliative sedation and it is considered as first-line drug (De Graeff, Dean, 2007; Rosengarten et al., 2009). In palliative care units, its use as a sedative reaches 93 to $98 \%$ of the patients (Krakauer et al., 2000; Elsayem et al., 2009). This drug is a water-soluble benzodiazepine and it has a short plasma half-life, an important factor especially in intermittent sedation, and its subcutaneous onset of action is 5-10 minutes (Midazolam, 2003). The recommended dose is easily titrated; in fact, it can be started with a dose between $0.5 \mathrm{mg} / \mathrm{h}$ and reach a usual effective dose of $1-20 \mathrm{mg} / \mathrm{h}$ 
(Cherny, Radbruch, 2009). It is a drug that can be combined with other medications used in palliative care and it can be administered intravenously and subcutaneously (online Palliative Care Formulary, 1991). This benzodiazepine is, with haloperidol, the usual election in the delirium treatment and is used stepwise to improve the patient's symptomatology. Midazolam chemical stability has been described with other drugs as morphine (LeBelle, Savard, Gagnon, 1995), fentanyl (Wilson, Schneider, Ravenscroft, 1998) or with diamorphine (Allwood, Brown, Lee, 1994).

Haloperidol is a butyrophenone and it is the antipsychotic usually employed in the treatment of the delirium (Porta et al., 2004) by its higher potency and lower secondary effects than the rest of the neuroleptic drugs. Haloperidol may also be administered intravenously and subcutaneously wherein low doses usually are required (1-10 mg/day) (Haloperidol, 2017; Hui et al., 2010). Its chemical stability has been described with other drugs such as morphine (LeBelle, Savard, Gagnon, 1995), tramadol (Negro et al., 2005), diamorphine hydrochloride (Collins et al., 1986) or hyoscine (Barcia et al., 2003).

In addition, haloperidol and midazolam can be used under combination in the same perfusion solution over several days to treat the delirium in hospitalized terminal patients or patients with palliative care attended by the domiciliary hospitalization units. Therefore, these admixtures have to be prepared in advance, especially for outpatients under sedative treatment; and physicochemical stability of the admixtures should be studied in function of the concentration of the drugs, the type of diluent and the storage conditions (temperature and presence of light).

To the best of our knowledge, chemical stability of both drugs is not clearly described yet when they are co-administered in the same admixture. Martínez-Gómez et al. (2007) have described just one combination of haloperidol and midazolam with 0.21 and $0.63 \mathrm{mg} \mathrm{mL}^{-1}$, respectively. The authors have used $0.9 \%$ sodium chloride solution and dextrose $5 \%$ as diluents and samples were stored at $24^{\circ} \mathrm{C}$. The authors have not found any significant change (a loss higher of $10 \%$ ) after fifteen days of storage.

Moreover, González-Valdivieso et al. (2009) have presented a description about the chemical stability of two ternary blends with haloperidol, midazolam and hyoscine butylbromide by using just $5 \%$ dextrose as diluent and storing the admixtures at room temperature. The studied concentrations were $0.2,1.2$ y $1.2 \mathrm{mg} \mathrm{mL}^{-1}$ and $0.8,1.2$ y $1.2 \mathrm{mg} \mathrm{mL}^{-1}$ for haloperidol, hyoscine butylbromide and midazolam, respectively. Then, just a change in the concentration of haloperidol was taken into account. The authors have found a 72-hour stability for the studied concentrations.
The previously studied conditions do not cover the usual concentration range of both drugs in the clinical use. In palliative care, administered midazolam concentrations can be even ten times higher than haloperidol.

Therefore, a thorough study about the physicochemical stability of these admixtures analyzing different levels of concentration, diluents and temperatures is needed to improve the clinical use of midazolam and haloperidol in palliative sedation.

\section{MATERIAL AND METHODS}

\section{Material}

Haloperidol, used as standard, was provided by Kern Pharma (Terrassa, Spain). Commercial samples of midazolam were acquired from Normon (Tres Cantos, Spain). Three different concentrations of midazolam were used to prepare the admixtures: $5 \mathrm{mg} / 5 \mathrm{~mL}$ (Lot \#L1JE), $15 \mathrm{mg} / 3 \mathrm{~mL}$ (Lot \#1JB1) and $50 \mathrm{mg} / 10 \mathrm{~mL}$ (Lot \#L0TR). Haloperidol $5 \mathrm{mg} / 1 \mathrm{~mL}$ (Lot \#K10) commercial samples were purchased from Esteve (Barcelona, Spain). Janssen (Beerse, Belgium) has provided the internal standard darunavir. HPLC-grade solvents as acetonitrile and water were obtained from Teknokroma (Barcelona, Spain) and methanol was purchased from Merck (Darmstadt, Germany). $\mathrm{KH}_{2} \mathrm{PO}_{4}$ was acquired from Panreac (Barcelona, Spain). $0.9 \%$ sodium chloride solution (Lot \#17B10E4U) and dextrose 5\% (Lot \#17B01E4D) were purchased from Baxter (Ribarroja del Turia, Spain).

\section{Methods}

\section{Turbidity measurement}

Turbidity of the samples was measured via MicroScan Turbidity Meter of Siemens Healthcare Diagnostics (Camberley, UK) comparing with a blank sample of $0.9 \%$ sodium chloride solution or $5 \%$ dextrose in function of the diluent of each sample. The measurement was done at different times: 0, 24, 72, 96 and 168 hours.

\section{pH determination}

$\mathrm{pH}$ was measured in a $\mathrm{pH} 500 \mathrm{pH}$ meter from Hanna Instruments (Padova, Italy). Buffer calibration solutions were acquired to Hamilton Bonaduz (Bonaduz, Switzerland). The determination was done at 0, 24, 72, 96 and 168 hours.

\section{HPLC concentration drugs measurement}

HPLC equipment was a Shimadzu LC-20AD pump with a DGU-20AS degasser and SIL-20AC autosampler, 
an oven CTO-10AS and a UV detector SPD-M20A with a deuterium lamp and the selected wavelength was $254 \mathrm{~nm}$. The employed column was a Tracer Excel 120 ODSB $(5 \mu \mathrm{m}, 15 \times 0.46 \mathrm{~cm})$ with a mobile phase of a mixture with $0.037 \mathrm{M} \mathrm{KH}_{2} \mathrm{PO}_{4}$ buffer solution $(\mathrm{pH}$ $4.3 \pm 0.1)$, acetonitrile and methanol $(40: 50: 10, \mathrm{v} / \mathrm{v})$ at a flow rate of $1.5 \mathrm{~mL} \mathrm{~min}{ }^{-1}$. The volume of injection was $10 \mu \mathrm{L}$. Darunavir was used as internal standard at final concentration of $2.5 \mu \mathrm{g} \mathrm{mL} \mathrm{mL}^{-1}$. The quantification of midazolam and haloperidol was done at the same time of $\mathrm{pH}$ determination and turbidity measurement: 0,24 , 72,96 and 168 hours.

\section{Preparation of stock solutions, calibration standard and quality control samples}

Samples were prepared using a stock solution of haloperidol in methanol $\left(1.0 \mathrm{mg} \mathrm{mL}^{-1}\right)$ and using commercial samples of midazolam $5 \mathrm{mg} / 5 \mathrm{~mL}$. Stock solutions were stored protected from light at $4{ }^{\circ} \mathrm{C}$. Both were diluted each day ten times until $0.10 \mathrm{mg} \mathrm{mL}^{-1}$ to prepare eight calibrators in a linear range concentrations from 8 to $80 \mu \mathrm{g} \mathrm{mL}^{-1}$ in case of midazolam and from to 2 to $12 \mu \mathrm{g} \mathrm{mL}^{-1}$ for haloperidol concentrations. Five calibration standards $(\mathrm{n}=5)$ and three quality control samples $(\mathrm{n}=3)$ were prepared. Internal standard darunavir was added from the stock solutions of $5000 \mu \mathrm{g} \mathrm{mL}^{-1}$ in methanol and diluting until a solution of $50 \mu \mathrm{g} \mathrm{mL} \mathrm{m}^{-1}$ of the IS was used to add $25 \mu \mathrm{L}$ to each calibrator. The final volume of each calibrator was $500 \mu \mathrm{L}$, including the added haloperidol, midazolam and IS volume and filling with mobile phase.

\section{Sample processing}

Nine admixtures with midazolam and haloperidol were prepared. The content of ampoules of midazolam and haloperidol were added to the $0.9 \%$ sodium chloride solution (SF) or $5 \%$ dextrose (SG) in viaflo plastic bags that not protected from light. Different range of concentrations was taken into account. In case of haloperidol, 10 and $20 \mathrm{mg}$ were added, and for midazolam, concentrations were from 30 to $200 \mathrm{mg}$. All the prepared samples were homogenate by agitation of $30 \mathrm{~s}$. Finally, seven of the studied admixtures were stored at room temperature $\left(20^{\circ} \mathrm{C}\right)$ and two of them were refrigerated $\left(4^{\circ} \mathrm{C}\right)$. The prepared admixtures are presented in Table I.

\section{Compatibility determination}

Compatibility was considered in the study of the apparition of turbidity, precipitate or colour change. The determination was done by visual inspection each day. Then, turbidity and $\mathrm{pH}$ were determined.

\section{Validation of the analytical method}

The analytical method was validated according to the guidelines of the agencies such as FDA (2001) and the European Medicines Agency (EMA) (2011). The studied parameters were specificity, selectivity, linearity, precision, accuracy, forced degradation studies and stock and working solutions stability. For more information, see the Supporting Information.

\section{Applicability of analytical method}

This assay was used to quantify the midazolam and haloperidol concentrations in perfusion solution. To determine this, $50 \mu \mathrm{L}$ of each sample were added to $425 \mu \mathrm{L}$ of mobile phase and $25 \mu \mathrm{L}$ of the IS solution. The study was done until one week after the sample preparation. Studied times were 0, 24, 72, 96 and 168 hours.

TABLE I - Midazolam/haloperidol admixtures

\begin{tabular}{lcccc}
\hline Sample & Haloperidol $(\mathbf{m g})$ & Midazolam $(\mathbf{m g})$ & Solution $(\mathbf{m L})$ & Temperature $\left({ }^{\mathbf{0}} \mathbf{C}\right)$ \\
\hline MIDHAL1 & 10 & 30 & $250 \mathrm{SF}$ & 20 \\
MIDHAL2 & 10 & 100 & $250 \mathrm{SF}$ & 20 \\
MIDHAL3 & 10 & 120 & $250 \mathrm{SF}$ & 20 \\
MIDHAL4 & 20 & 100 & $250 \mathrm{SF}$ & 20 \\
MIDHAL5 & 20 & 30 & $250 \mathrm{SF}$ & 20 \\
MIDHAL6 & 10 & 200 & $250 \mathrm{SG}$ & 20 \\
MIDHAL7 & 20 & 200 & $250 \mathrm{SG}$ & 20 \\
MIDHAL8 & 20 & 200 & $250 \mathrm{SF}$ & 4 \\
MIDHAL9 & 20 & & $250 \mathrm{SG}$ & 4 \\
\hline
\end{tabular}




\section{RESULTS}

Visual inspection of the midazolam and haloperidol admixtures did not report any change about appearance, colour change or apparition of turbidity or precipitate. Turbidity measurement was done and the obtained results in function of the time and the total variance are presented in Table II.

Additionally, the $\mathrm{pH}$ values were determined in function of the time to evaluate a possible change in the admixtures. Table III collects the $\mathrm{pH}$ values for the admixtures at $0,24,72,96$ and 168 hours. This table also presents the variance between the maximum and minimum values.

Finally, the concentration of the drugs was measured by HPLC. The obtained results are presented in Table IV. In case of initial time ( $\mathrm{T}=0)$, drugs are presented by their concentration. For the rest of the measurements, the remaining percentage is presented for each drug.

\section{DISCUSSION}

Recent study (Kotfis et al., 2017) exposed than midazolam is one of the most selected sedative drugs for more than 24-hour treatments and the preferred agent for delirium treatment was haloperidol.

The use of different drugs under combination allows the administrations of smaller volumes, reducing the number of pumps and preventing stress on the veins. However, to know if an admixture with two or more drugs can be prepared, the physicochemical stability has to be studied (Estan-Cerezo et al., 2017).

Sedatives are frequently used towards the end of life for delirium/agitation and even more in palliative patients who had significantly higher total daily midazolam doses days around death (Schildmann, 2018). For MartínezGómez et al. (2007) who studied midazolam: haloperidol concentration ratio was 3:1; and González-Valdivieso et al. (2009) studied two ternary blends with a maximum

TABLE II - Turbidity measurements in function of the time

\begin{tabular}{lcccccc}
\hline \multirow{2}{*}{ Sample } & \multicolumn{3}{c}{ Time (hours) } & \multirow{2}{*}{ Variance } \\
\cline { 2 - 5 } & $\mathbf{0}$ & $\mathbf{2 4}$ & $\mathbf{7 2}$ & $\mathbf{9 6}$ & $\mathbf{1 6 8}$ & -0.01 \\
MIDHAL1 & 0.01 & 0.01 & 0.01 & 0.01 & 0.00 & -0.02 \\
MIDHAL2 & 0.04 & 0.03 & 0.00 & 0.02 & 0.02 & -0.02 \\
MIDHAL3 & 0.03 & 0.02 & 0.00 & 0.01 & 0.01 & -0.01 \\
MIDHAL4 & 0.02 & 0.03 & 0.02 & 0.00 & 0.01 & 0.00 \\
MIDHAL5 & 0.02 & 0.03 & 0.00 & 0.02 & 0.02 & 0.01 \\
MIDHAL6 & 0.04 & 0.03 & 0.04 & 0.04 & 0.05 & 0.00 \\
MIDHAL7 & 0.03 & 0.03 & 0.02 & 0.02 & 0.03 & -0.02 \\
MIDHAL8 & 0.03 & 0.04 & 0.00 & 0.03 & 0.01 & -0.01 \\
MIDHAL9 & 0.05 & 0.03 & 0.05 & 0.04 & 0.04 & \\
\hline
\end{tabular}

TABLE III - $\mathrm{pH}$ determinations in function of the time for the midazolam/haloperidol admixtures

\begin{tabular}{lcccccc}
\hline \multirow{2}{*}{ Sample } & \multicolumn{5}{c}{ Time (hours) } & \multirow{2}{*}{ Variance } \\
\cline { 2 - 5 } & $\mathbf{0}$ & $\mathbf{2 4}$ & $\mathbf{7 2}$ & $\mathbf{9 6}$ & $\mathbf{1 6 8}$ & \\
\hline MIDHAL1 & 3.67 & 3.65 & 3.62 & 3.64 & 3.67 & 0.05 \\
MIDHAL2 & 3.50 & 3.46 & 3.44 & 3.46 & 3.44 & 0.06 \\
MIDHAL3 & 3.49 & 3.46 & 3.45 & 3.46 & 3.46 & 0.04 \\
MIDHAL4 & 3.43 & 3.40 & 3.40 & 3.38 & 3.41 & 0.05 \\
MIDHAL5 & 3.30 & 3.30 & 3.31 & 3.31 & 3.30 & 0.01 \\
MIDHAL6 & 3.67 & 3.67 & 3.60 & 3.65 & 3.62 & 0.07 \\
MIDHAL7 & 3.39 & 3.33 & 3.27 & 3.26 & 3.33 & 0.13 \\
MIDHAL8 & 3.39 & 3.36 & 3.34 & 3.35 & 3.38 & 0.05 \\
MIDHAL9 & 3.31 & 3.30 & 3.28 & 3.32 & 3.33 & 0.05 \\
\hline
\end{tabular}


Midazolam and haloperidol for palliative sedation: physicochemical stability and compatibility of parenteral admixtures

TABLE IV - Mean percentages values of drugs concentrations at time zero and remaining percentages in the admixtures at different times

\begin{tabular}{|c|c|c|c|c|c|c|c|c|c|c|}
\hline \multirow{3}{*}{ Sample } & \multicolumn{10}{|c|}{ Time (hours) } \\
\hline & \multicolumn{2}{|c|}{$\mathbf{0}$} & \multicolumn{2}{|c|}{24} & \multicolumn{2}{|c|}{72} & \multicolumn{2}{|c|}{96} & \multicolumn{2}{|c|}{168} \\
\hline & $\begin{array}{c}\mathrm{Hal}^{*} \\
\left(\mathrm{mg} \mathrm{mL}^{-1}\right)\end{array}$ & $\begin{array}{c}\text { Mid }^{* *} \\
\left(\mathrm{mg} \mathrm{mL}^{-1}\right)\end{array}$ & $\begin{array}{l}\text { Hal } \\
(\%)\end{array}$ & $\begin{array}{l}\text { Mid } \\
\text { (\%) }\end{array}$ & $\begin{array}{l}\text { Hal } \\
(\%)\end{array}$ & $\begin{array}{l}\text { Mid } \\
(\%)\end{array}$ & $\begin{array}{l}\text { Hal } \\
(\%)\end{array}$ & $\begin{array}{l}\text { Mid } \\
(\%)\end{array}$ & $\begin{array}{l}\text { Hal } \\
(\%)\end{array}$ & $\begin{array}{l}\text { Mid } \\
\text { (\%) }\end{array}$ \\
\hline MIDHAL1 & 0.0347 & 0.1906 & 96.18 & 94.38 & 102.82 & 107.68 & 93.13 & 109.31 & 101.67 & 68.91 \\
\hline MIDHAL2 & 0.0308 & 0.3883 & 99.29 & 97.50 & 102.86 & 106.24 & 101.33 & 108.26 & 108.96 & 102.77 \\
\hline MIDHAL3 & 0.0335 & 0.4889 & 108.58 & 100.42 & 96.99 & 101.19 & 91.35 & 98.86 & 88.42 & 86.52 \\
\hline MIDHAL4 & 0.0637 & 0.4053 & 96.69 & 96.32 & 98.74 & 103.51 & 101.22 & 106.85 & 93.74 & 91.92 \\
\hline MIDHAL5 & 0.0547 & 0.6533 & 104.73 & 103.31 & 106.77 & 107.98 & 105.12 & 104.86 & 103.99 & 103.25 \\
\hline MIDHAL6 & 0.0331 & 0.1842 & 107.22 & 103.52 & 95.54 & 101.28 & 101.56 & 108.62 & 107.41 & 72.14 \\
\hline MIDHAL7 & 0.0628 & 0.7305 & 101.92 & 98.99 & 97.51 & 99.25 & 92.32 & 93.83 & 91.56 & 95.78 \\
\hline MIDHAL8 & 0.0598 & 0.6648 & 96.34 & 94.56 & 99.43 & 102.69 & 102.34 & 105.77 & 93.12 & 98.43 \\
\hline MIDHAL9 & 0.0621 & 0.7137 & 104.83 & 102.50 & 96.17 & 98.28 & 101.62 & 103.29 & 101.06 & 108.59 \\
\hline
\end{tabular}

Hal $^{*}=$ Haloperidol; Mid**= Midazolam.

concentration ratio between them of about $6: 1$. In palliative care, administered midazolam concentrations can be even ten times higher than haloperidol like the concentrations analyzed in our study (midazolam: haloperidol concentration ratios since $3: 1$ to $10: 1$ ).

Concentrations of haloperidol measured by HPLC are from 0.0308 to $0.0637 \mathrm{mg} \mathrm{mL}^{-1}$ and in case of midazolam, it ranged are from 0.1842 to $0.7305 \mathrm{mg} \mathrm{mL}^{-1}$ covering a wide broad of possible admixtures for the clinical use of both drugs (Table IV).

In case of midazolam and haloperidol, first of all, the appearance of the admixtures was shown by visual inspection, checking the no apparition of turbidity, precipitate or colour change. All the prepared admixtures have good appearance during the studied days.

Thus, the study of the turbidity measurement was done. In Table II, it is possible to check the evolution of the turbidity in function of the time. This analysis was done because if a precipitate appears, the value of the turbidity will increase strongly. In our case, most of the studied admixtures have regular values, accepting a variance due of the instrument of 0.01 . Some of the admixtures have an incongruent value, with lower values than the rest of the values of the same admixture in function of the time. However, the global variance does not show any significant trend increase in any of the studied admixtures. Furthermore, turbidity measurement was done as an initial test to establish the whether there is an apparition of precipitate or none and the determinations will be corroborated with the other two experimental techniques.
The determination of the $\mathrm{pH}$ can give another idea about a possible change in the composition of the admixtures. Table III shows the determination of this parameter after the preparation of the admixtures and its evolution until 168 hours (seven days). In eight of the prepared admixtures, variance of the $\mathrm{pH}$ values was lower than 0.07 units of $\mathrm{pH}$. Just in case of sample MIDHAL 7 the variance was 0.13 units. This little variance corresponds with no remarkable change in the compositions of the admixtures.

However, the main experimental employed technique was the HPLC by following a validated assay by the FDA (2001) and EMA (2011) requirements. In the Supporting Information, all the relevant information about specificity, selectivity, linearity, short-term stability and forced degradation studies is presented. All the studied parameters were found satisfactory.

The obtained data by the HPLC determination are presented in Table IV. In the first two columns, the concentration of haloperidol and midazolam, respectively in each admixture are presented. Then, for the rest of the day the percentage of remaining drugs are presented. The acceptable concentration range for the drugs is from $90 \%$ to $110 \%$. In our admixtures, all the studied samples are inside this range until the fourth day.

On the seventh day, the concentration is lessen in some of the samples. Three of the seven admixtures stored at room temperature showed concentrations of one or both drugs lower than the $90 \%$ (MIDHAL1, MIDHAL3 and MIDHAL5). Then, the chemical stability can be assigned as a maximum of 96 hours when samples are stored at 
$20{ }^{\circ} \mathrm{C}$. There is not a significant difference in function of the diluent.

The two refrigerated samples (MIDHAL 8 and MIDHAL9) showed a larger chemical stability and they are stable even on the seventh day.

We have found a lower value than the previously reported stability (Martínez-Gómez et al., 2007) for the binary blends. Midazolam and haloperidol admixtures do not need really larger stabilities to be used for perfusion. Then, four days can be enough for palliative sedation.

Finally, our Pharmacy Service follows the microbiological risk matrix (Rosales Cabrera, López Cabezas, García Salom, 2014) to minimize the possible risk by microbiological contamination. In case of prepared admixtures of midazolam and haloperidol stored at room temperature, the assigned maximum stability is 48 hours. This value is higher in case of refrigerated samples until fourteen days. Then, midazolam and haloperidol admixtures stored at $20^{\circ} \mathrm{C}$ can be considered stable until 48 hours after their preparation. In case of home patients under sedative treatment, samples should be refrigerated after the preparation until its use to increase this range of stability until the seventh day.

In case of the samples stored at room temperature acceptable chemical concentrations are obtained until the fourth day. However, by the microbiological risk matrix assignment 48 hours of stability can be assured. This time is enough for hospitalized patients who need midazolam and haloperidol admixtures for palliative sedation.

When samples are stored refrigerated, the adequate values of concentrations are obtained until the seventh day. In addition, seven days are adequate for microbiological stability. Then, for home patients, samples should be refrigerated after their preparation.

A validated method following the agencies requirements was followed with good results of precision, accuracy and stability of the working solutions to quantify midazolam and haloperidol admixtures.

\section{ACKNOWLEDGEMENTS}

Authors want to thank Kern Pharma and Janssen for kindly providing their raw materials.

\section{CONFLICT OF INTEREST}

The authors declare that they have no conflict of interest.
Funding: This work was partially supported by European Regional Development Fund (ERDF) and the European Social Fund (ESF) [grant number PEJ2014-A-06341].

\section{REFERENCES}

Allwood MC, Brown PW, Lee M. Stability of injections containing diamorphine and midazolam in plastic syringes. Int J Pharm Pract. 1994;3(1):57-9.

Barcia E, Reyes R, Azuara ML, Sánchez Y, Negro S. Compatibility of haloperidol and hyoscine-N-butyl bromide in mixtures for subcutaneous infusion to cancer patients in palliative care. Support Care Cancer. 2003;11(2):107-13.

Cherny NI, Radbruch L. Board of the European Association for Palliative Care: European Association for Palliative Care (EAPC) recommended framework for the use of sedation in palliative care. Palliat Med. 2009;23(7):581-93.

Collins AJ, Abethell JA, Holmes SG, Brain R. Stability of diamorphine hydrochloride with haloperidol in prefilled syringes for continuous subcutaneous administration. J Pharm Pharmacol. 1986;38(S12):51p.

De Graeff A, Dean M. Palliative sedation therapy in the last weeks of life: a literature review and recommendations for standards. J Palliat Med. 2007;10(1):67-85.

Elsayem A, Curry III E, Boohene J, Munsell MF, Calderon B, Hung $\mathrm{F}$, et al. Use of palliative sedation for intractable symptoms in the palliative care unit of a comprehensive cancer center. Support Care Cancer. 2009;17(1):53-9.

EMA. European Medecines Agency. Guideline on bioanalytical method validation. Committee for Medicinal Products for Human Use (CHMP) July 2011. http://www.ema.europa.eu/ docs/en_GB/document_library/Scientific_guideline/2011/08/ WC500109686.pdf.

Estan-Cerezo G, Matoses-Chirivella C, Soriano-Irigaray L, Murcia-López AC, Rodríguez-Lucena FJ, Navarro-Ruiz A. Stability and compatibility of ondansetron with haloperidol in parenteral admixtures. Eur J Hosp Pharm. 2017. doi: 10.1136/ ejhpharm-2016-001200. 
FDA. U.S. Department of Health and Human Services, Food and Drug Administration, Center for Drug Evaluation and Research (CDER), Center for Veterinary Medicine (CVM). Guidance for Industry Bioanalytical Method Validation. May 2001. BP. http://www.fda.gov/downloads/Drugs/ GuidanceComplianceRegulatoryInformation/Guidances/ ucm070107.pdf.

González-Valdivieso J, Carril Avilés M, Borrás Alemanr C, Romero Crespo I, Jiménez Torres NV. Estabilidad de haloperidolbutilescopolamina-midazolam en sistemas de infusión continua de 24 Horas. Medicina Paliativa. 2009;16(2):78-83.

Haloperidol [Bula]. Valencia: AEMPS, 2017. [Cited 2017 Mar 3]. Available from: https://www.aemps.gob.es/cima/pdfs// ft/58345/FT_58345.pdf.

Hui D, Bush SH, Gallo LE, Palmer JL, Yennurajalingam S, Bruera E. Neuroleptic dose in the management of delirium in patients with advanced cancer. J Pain Symptom Manag. 2010;39(2):186-96.

Jenke DR. Chromatographic method validation: a review of current practices and procedures. II. Guidelines for primary validation parameters. J Liq Chrom Rel Technol 1996; 19:73757.

Kotfis K, Zegan-Barańska M, Żukowski M, Kusza K, Kaczmarczyk M, Ely EW. Multicenter assessment of sedation and delirium practices in the intensive care units in Poland - is this common practice in Eastern Europe? BMC Anesthesiology. $2017 ; 17: 120$.

Krakauer EL, Penson RT, Truog RD, King LA, Chabner BA, Lynch TJ Jr. Sedation for intractable distress of a dying patient: Acute palliative care and the principle of double effect. Oncologist. 2000;5(1):53-62.

LeBelle MJ, Savard C, Gagnon A. Compatibility of morphine and midazolam or haloperidol in parenteral admixtures. Can J Hosp Pharm. 1995;48(1):155-60.
Martínez-Gómez MA, Jiménez-Arenas V, Merino-Sanjuán M, Medina-Hernández MJ, Borrás-Almenar C, Jiménez-Torres V. Stability studies of binary mixtures of haloperidol and/or midazolam with other drugs for parenteral administration. J Palliat Med. 2007;10(6):1306-11.

Midazolam [Bula]. Madrid: Laboratorios Normon; 2003. [Cited 2017 Mar 3]. Available from: https://www.aemps.gob.es/cima/ pdfs//ft/63936/FT_63936.pdf.

Negro S, Martin A, Azuara ML, Sánchez Y, Barcia E. Stability of tramadol and haloperidol for continuous infusion at home. J Pain Symptom Manag. 2005;30(2):192-99.

Palliative Care Formulary [Bula]. Nottingham: Palliativedrugs. com; 1991. [Cited 2017 Mar 3]. Available from: www. palliativedrugs.co.uk

Porta J, Serrano G, González J, Sánchez D, Tuca A, GómezBatiste X. Delirium en cuidados paliativos oncológicos: revisión. Psicooncología. 2004;1(2/3):113-30.

Rosales Cabrera AMM, López Cabezas C, García Salom, P. Diseño de una matriz de riesgo para la valoración de los preparados estériles en los centros sanitarios. Farm Hosp. 2014;38(3):202-10.

Rosengarten OS, Lamed Y, Zisling T, Feigin A, Jacobs JM. Palliative sedation at home. J. Palliat. Care. 2009;25(1):5-11.

Schildmann E, Pörnbacher S, Kalies H, Bausewein C. 'Palliative sedation'? A retrospective cohort study on the use and labelling of continuously administered sedatives on a palliative care unit. Palliat Med. 2018. doi:10.1177/0269216318764095.

Trissel LA. Avoiding common flaws in stability and compatibility studies of injectable drugs. Am J Hosp Pharm. 1983;40:1159-60.

Wilson KM, Schneider JJ, Ravenscroft PJ. Stability of midazolam and fentanyl in infusion solutions. J. Pain Symptom Manage. 1998;16(1):52-8.

Received for publication on $21^{\text {st }}$ June 2017 Accepted for publication on $05^{\text {th }}$ April 2018 